\title{
Properties of Biomimetic Artificial Spider Silk Fibers Tuned by PostSpin Bath Incubation
}

\author{
Gabriele Greco ${ }^{1,+} \oplus$, Juanita Francis ${ }^{2,+}$, Tina Arndt ${ }^{2}$, Benjamin Schmuck ${ }^{2}{ }^{\oplus}$, \\ Fredrik G. Bäcklund ${ }^{2}$, Andreas Barth ${ }^{3}{ }^{-}$, Jan Johansson ${ }^{2}$, Nicola M. Pugno ${ }^{1,4, *(\mathbb{D}}$ \\ and Anna Rising 2,5,*(D) \\ 1 Laboratory of Bio-Inspired, Bionic, Nano, Meta, Materials \& Mechanics, Department of Civil, \\ Environmental and Mechanical Engineering, University of Trento, Via Mesiano 77, 38123 Trento, Italy; \\ gabriele.greco-2@unitn.it \\ 2 Department of Neurobiology, Care Sciences and Society, Karolinska Institutet, Neo, 14186 Huddinge, \\ Sweden; juanita.francis@ki.se (J.F.); tina.arndt@ki.se (T.A.); benjamin.schmuck@ki.se (B.S.); \\ fredrik.backlund.2@ki.se (F.G.B.); janne.johansson@ki.se (J.J.) \\ 3 Department of Biochemistry and Biophysics, The Arrhenius Laboratories for Natural Sciences, \\ Stockholm University, 10691 Stockholm, Sweden; barth@dbb.su.se \\ 4 School of Engineering and Materials Science, Queen Mary University of London, Mile End Road, \\ London E1 4NS, UK \\ 5 Department of Anatomy, Physiology and Biochemistry, Swedish University of Agricultural Sciences, \\ 75007 Uppsala, Sweden \\ * Correspondence: nicola.pugno@unitn.it (N.M.P.); anna.rising@ki.se (A.R.); Tel.: +39-0461-282525; \\ Fax: +39-0461-282599 (N.M.P.); Tel./Fax: +46-704-10-6997 (A.R.) \\ + These authors contributed equally.
}

Academic Editor: Yasumoto Nakazawa Received: 27 June 2020; Accepted: 13 July 2020; Published: 16 July 2020

\begin{abstract}
Efficient production of artificial spider silk fibers with properties that match its natural counterpart has still not been achieved. Recently, a biomimetic process for spinning recombinant spider silk proteins (spidroins) was presented, in which important molecular mechanisms involved in native spider silk spinning were recapitulated. However, drawbacks of these fibers included inferior mechanical properties and problems with low resistance to aqueous environments. In this work, we show that $\geq 5 \mathrm{~h}$ incubation of the fibers, in a collection bath of $500 \mathrm{mM} \mathrm{NaAc}$ and $200 \mathrm{mM}$ $\mathrm{NaCl}$, at pH 5 results in fibers that do not dissolve in water or phosphate buffered saline, which implies that the fibers can be used for applications that involve wet/humid conditions. Furthermore, incubation in the collection bath improved the strain at break and was associated with increased $\beta$-sheet content, but did not affect the fiber morphology. In summary, we present a simple way to improve artificial spider silk fiber strain at break and resistance to aqueous solvents.
\end{abstract}

Keywords: fiber; tensile testing; mechanical properties; spinning

\section{Introduction}

In recent decades, spider silks and their extraordinary mechanical and biological properties have gained interest from the scientific community as well as from the industry [1-4]. Spider silk is envisioned as an interesting material for applications in tissue engineering [2,5-11], the textile industry $[12,13]$ and as reinforcement in composites [14]. Unfortunately, spiders produce small amounts of silk and they are difficult to farm due to their cannibalistic, predatory, and solitary nature [15]. To overcome this problem, production of recombinant silk proteins (spidroins) in heterologous hosts has been seen as a plausible solution that also would be beneficial from an environmental point of view $[16,17]$. Several protocols for recombinant spidroin production in different prokaryotic and eukaryotic systems have been 
published [18-24] and there are even protocols for spidroin production in mammalian hosts [25-27]. Common problems encountered when producing spidroins in these hosts have been low protein yields and premature aggregation during expression, which resulted in aggregated target proteins that required solubilization in harsh solvents such as hexafluoroisopropanol (HFIP) [23,28]. Such conditions denatured the proteins and were incompatible with a biomimetic spinning procedure [16].

Spiders are able to keep the spidroins soluble during storage in the glands at an impressive concentration of 30-50\% (w/v) [29], and they convert the protein solution into solid fibers using a drop in $\mathrm{pH}$ to $<5.7$ and shear forces [30]. Recently, this high solubility has been achieved for designed recombinant spidroins that were purified from E. coli and kept, in an aqueous buffer, at pH 8.0 [31,32]. Moreover, these recombinant spidroins have been spun into continuous fibers in biomimetic spinning setups where the fibers were formed by extrusion of a highly concentrated protein solution into a collection bath (pH 5.0 aqueous buffer) [31-33] (Figure 1). Unfortunately, the artificially spun fibers produced in this way do not match the native fibers in terms of mechanical properties and they are sensitive to wet environments [31-33].

In this work, we show that the strain at break of biomimetic artificial spider silk fibers can be improved by means of increased incubation time in the collection bath. Notably, after $\geq 5 \mathrm{~h}$ incubation, the fibers do not dissolve in deionized water $\left(\mathrm{dH}_{2} \mathrm{O}\right)$ or phosphate buffered saline (PBS). On the basis of our findings we present a simple protocol to tune the mechanical properties and avoid water-solubility of biomimetic artificial spider silk fiber.

\section{Results}

The miniature spidroin NT2RepCT was produced and concentrated to $300 \mathrm{mg} / \mathrm{mL}$ and spun into fibers essentially as previously described [31]. Briefly, a syringe pump was used to extrude the protein solution through a pulled glass capillary into an aqueous buffer at pH 5.0 (500 mM NaAc and $200 \mathrm{mM} \mathrm{NaCl}$, Figure 1a). The fibers were either immediately taken up from the collection bath onto a motorized wheel with diapositive slide frames attached ( $0 \mathrm{~h}$ incubation) or collected onto a roller that was submerged in the collection bath (Figure 1a). The immersed roller was left in the bath for fixed periods of time ranging between 1 and $48 \mathrm{~h}$, where after it was removed from the bath, the fibers were collected from the roller, dried in air, and tested for water solubility, as well as characterized by tensile testing using Fourier transform infrared (FTIR) spectroscopy, light microscopy, and scanning electron microscopy (SEM).

a)

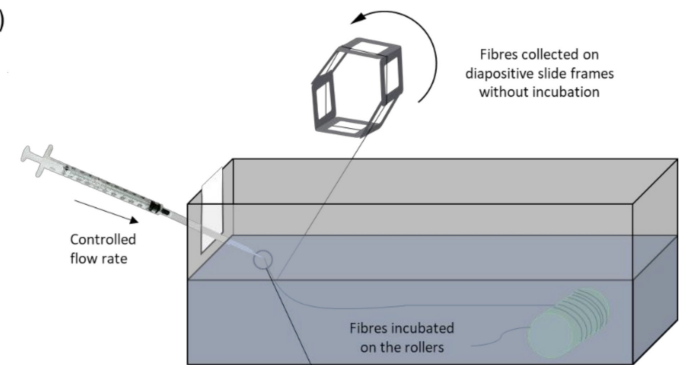

b)

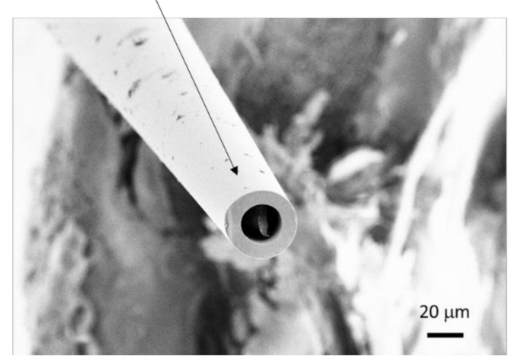

Figure 1. (a) Schematic diagram of the spinning setup. (b) SEM picture of a capillary used to spin the artificial spider silk fibers. 
First, we investigated the resistance of fibers to aqueous solvents. Dried fibers were placed in either $\mathrm{dH}_{2} \mathrm{O}$ or PBS and their integrity was observed immediately by the naked eye after $24 \mathrm{~h}$, $48 \mathrm{~h}$, and 1 week. Fibers that were collected immediately and the fibers that were incubated for 1 and $2 \mathrm{~h}$, respectively, shrunk and dissolved immediately when they came into contact with $\mathrm{dH}_{2} \mathrm{O}$ or PBS. In contrast, fibers that were incubated in the collection bath for 12 and $48 \mathrm{~h}$ decreased slightly in length immediately upon contact with the aqueous solvents but remained intact for more than $48 \mathrm{~h}$ and 1 week in $\mathrm{dH}_{2} \mathrm{O}$ and $\mathrm{PBS}$, respectively. To further pinpoint the timepoint for conversion to a more resistant type, we incubated a second set of fibers for $3,5,5.5$, and $6 \mathrm{~h}$ in the collection bath before performing the solubility assays. The results showed that $\leq 3 \mathrm{~h}$ incubation resulted in fibers that dissolved in aqueous solvents but incubation in the collection bath for $\geq 5 \mathrm{~h}$ resulted in fibers that remained intact (Table S1).

FTIR spectroscopy of the NT2RepCT fibers showed an increased absorbance around $1630-1620 \mathrm{~cm}^{-1}$ in the amide I region for fibers incubated for $6 \mathrm{~h}$ or longer, which is consistent with increased $\beta$-sheet content (Figure 2a). To explore this further, second derivative spectra were generated in which negative bands indicated the positions of component bands in the respective absorbance spectrum (Figure 2b). Incubation in the spinning buffer led to clear changes in the second derivative spectra, i.e., a new component appeared near $1625 \mathrm{~cm}^{-1}$ and the high wavenumber band near $1695 \mathrm{~cm}^{-1}$ became more distinct. These features are typical for antiparallel $\beta$-sheets, which are rather flat and extended [34-36]. Double difference spectra (absorbance at time $\times$ minus absorbance at time 0 , not shown) showed a decrease in absorbance near $1650 \mathrm{~cm}^{-1}$ where the main components of the spectrum at $0 \mathrm{~h}$ incubation time were observed in the second derivative spectrum. This indicated that the initial structure was transformed to an extended $\beta$-sheet structure upon prolonged incubation.
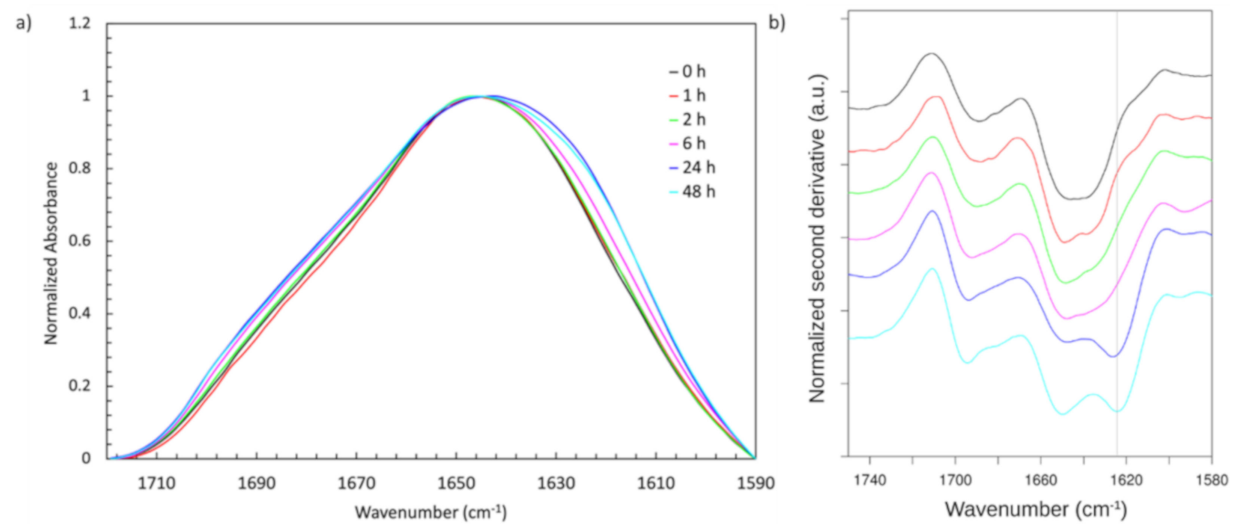

Figure 2. (a) Averaged, normalized, and baseline-subtracted absorbance spectra in the amide I region of NT2RepCT fibers incubated in spinning buffer for 0, 1, 2, 6, 24, and 48 h; (b) Normalized second derivatives of the absorbance spectra of NT2RepCT fibers incubated in spinning buffer for $0 \mathrm{~h}$ (black), $1 \mathrm{~h}$ (red), $2 \mathrm{~h}$ (green), $6 \mathrm{~h}$ (purple), $24 \mathrm{~h}$ (blue), and $48 \mathrm{~h}$ (turquoise). The gray vertical line indicates the position of the $\beta$-sheet band observed after 24 and $48 \mathrm{~h}$ of incubation.

Next, we analyzed the mechanical properties of the fiber. The incubation time seemed to not affect the strength or Young's modulus significantly over the course of the first $24 \mathrm{~h}$ of incubation (Figure 3a,b and Table S1). In pairwise comparisons among the groups, we noticed a significant difference only between the fibers incubated for 6 and $48 \mathrm{~h}$. Notably, the strain at break increased significantly during the first $2 \mathrm{~h}$ of incubation (Figure $3 \mathrm{c}$ and Table S1). The mean strain values obtained for fibers incubated for 0,1 , and $2 \mathrm{~h}$ more than doubled for each hour of incubation, thereafter the strain remained unchanged for the 6 and $24 \mathrm{~h}$ samples. The fibers that were incubated for 6 and $24 \mathrm{~h}$ did not show any significantly altered properties as compared with $2 \mathrm{~h}$ incubation for any of the investigated mechanical parameters (Figure 3a-d and Table S1). In contrast, the fibers that were incubated for $48 \mathrm{~h}$ presented a lower strain at break and toughness modulus as compared with the fibers incubated for $6 \mathrm{~h}$. The qualitative analysis of the stress-strain graphs showed that, after $\geq 1 \mathrm{~h}$ incubation, a clear yield point emerged, which meant that the fibers become plastic and more deformable (Figure S1). 
In general, the best performing fibers (obtained after 2-6 h of incubation) had strain values comparable to native silk fibers but ultimate tensile strength was $10-20 \%$ of that of most spider silks [37].

a)
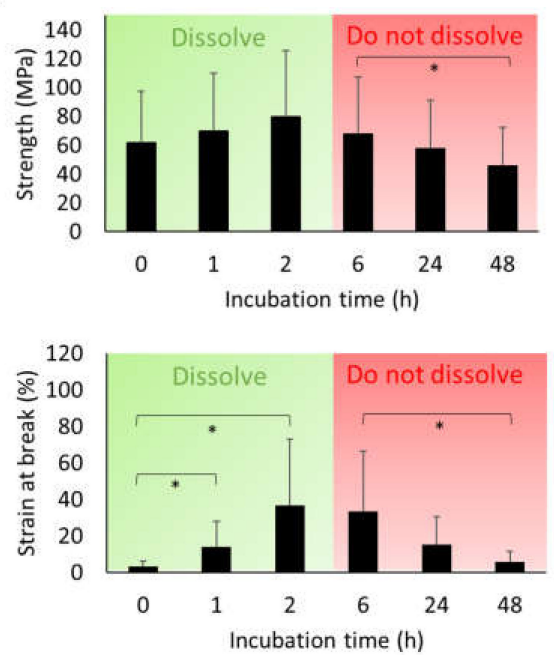

b)

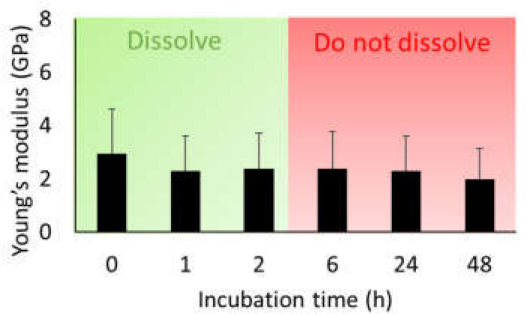

d)

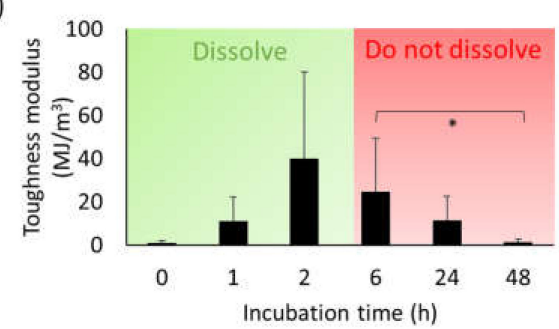

Figure 3. Mechanical properties of the fibers vs. the incubation time in the collection bath. (a) Strength (MPa); (b) Young's modulus (GPa); (c) Strain at break (mm/mm); (d) toughness modulus $\left(\mathrm{MJ} \mathrm{m}^{-3}\right)$. Green indicates that the fibers dissolved and red that they stayed intact when submerged in either $\mathrm{dH}_{2} \mathrm{O}$ or PBS. Stars indicate that the differences were statisitically significant $(p<0.05)$. Depending on the typology, the following numbers of fibers were tested: 17 for $0 \mathrm{~h}, 6$ for $1 \mathrm{~h}, 5$ for $2 \mathrm{~h}, 34$ for $6 \mathrm{~h}, 17$ for $24 \mathrm{~h}$, and 10 for $48 \mathrm{~h}$. * indicates $p<0.05$.

The fiber morphology was unaffected by both incubation time and method of collection (frames vs. roller). However, we found that most fibers exhibited a pronounced "dual fiber" appearance with a concomitant dumbbell-shaped cross-section (Figure 4, Figure 5, and Figure S3). Some fibers were a bit flattened and had a more elliptical cross-section (Figure 5). The reason for this is not clear, but it is not directly due to a defect in the shape of the capillary nozzle, which was found to be circular (Figure 1b). In addition, the morphology of the fibers was not always uniform along the same fiber.
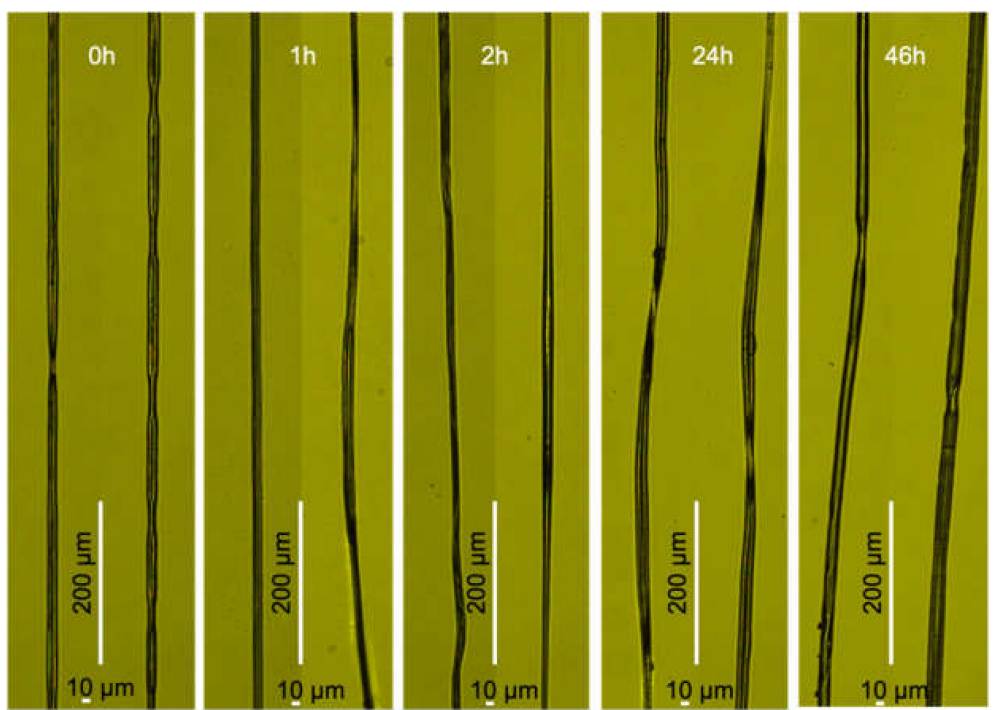

Figure 4. Light microscopy images of fibers with indicated incubation times. 
a)
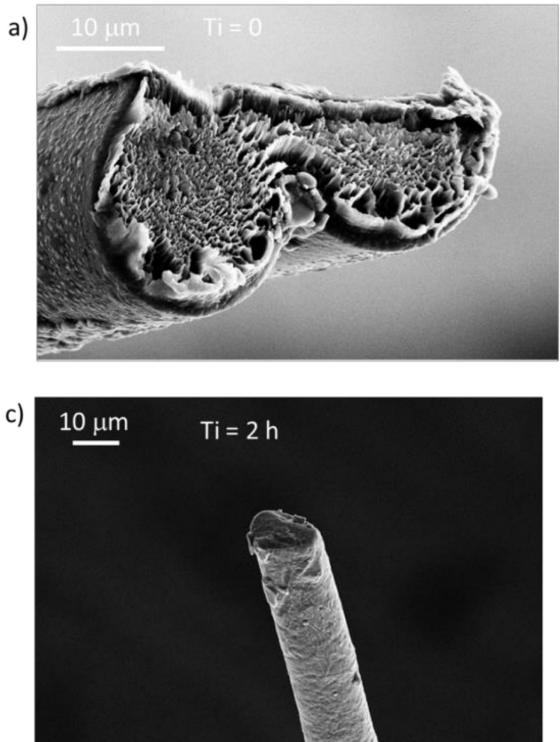

e)

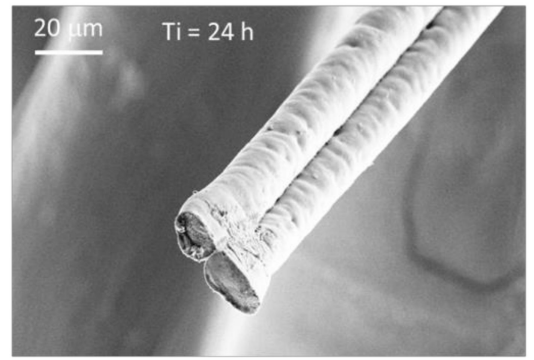

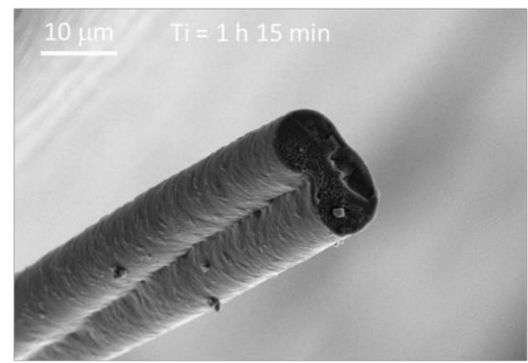

d)

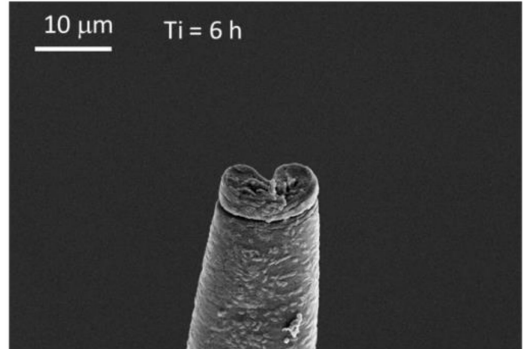

f) $20 \mu \mathrm{m}$

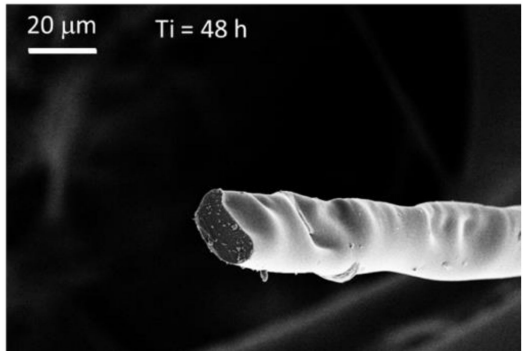

Figure 5. Fracture sections of fibers that were incubated for (a) $0 \mathrm{~h}$; (b) $1 \mathrm{~h}$ and $15 \mathrm{~min}$; (c) $2 \mathrm{~h}$; (d) $6 \mathrm{~h}$; (e) $24 \mathrm{~h}$; (f) $48 \mathrm{~h}$ in the collection bath.

\section{Discussion}

Herein, we explore possible means to modulate the properties of artificial spider silk fibers by tuning the incubation period in the collection bath. In order to allow incubation of the fibers in the collection bath with minimal fiber handling, we constructed a roller that was motorized and submerged into the collection bath, and optionally the fibers could be immediately collected onto rotating frames in air (Figure 1a). In this manner, fibers were collected at an even and fixed speed.

Incubation times $\geq 5 \mathrm{~h}$ resulted in fibers that were resistant to aqueous environments and these fibers behaved similar to native silk in that they initially contracted upon contact with $\mathrm{dH}_{2} \mathrm{O}$ or PBS but after that remained intact [38]. In contrast, the fibers that were incubated for $3 \mathrm{~h}$ or less, almost immediately dissolved in contact with $\mathrm{dH}_{2} \mathrm{O}$ or PBS. Because $\beta$-sheet crystalline structures contribute to the stability of silk biomaterials in a wide range of environments, including in water [11], we investigated, using FTIR spectroscopy, if increased $\beta$-sheet content could be related to the decrease in fiber solubility. For fibers incubated for $6 \mathrm{~h}$ and longer, there was indeed an increased $\beta$-sheet content, most likely due to the formation of antiparallel $\beta$-sheets, as shown by increased absorbance around $1630-1620 \mathrm{~cm}^{-1}$ as compared with fibers incubated for $2 \mathrm{~h}$ or less (Figure 2). Thus, the observed increase in $\beta$-sheet content coincides with the conversion from soluble to insoluble fibers. It is not known which part of the NT2RepCT protein is responsible for the structural conversion, but previous reports have shown that the $\mathrm{C}$-terminal domain converted to $\beta$-sheet structures in response to low $\mathrm{pH}[30,39]$ and that the poly-Ala blocks of the repetitive region could form helical or $\beta$-strand conformations in the NT2RepCT fiber [34]. The NT is unlikely to contribute to the increased $\beta$-sheet content since it is $\alpha$-helical also at a low $\mathrm{pH}[40]$.

The mechanical parameter that was most affected by incubation in the collection bath was strain at break (Figure 3). Fibers that were incubated for $1-2 \mathrm{~h}$ showed significantly increased strain as 
compared with the fibers that were immediately collected, but increased incubation time beyond $2 \mathrm{~h}$ did not improve the properties further, and after $48 \mathrm{~h}$, we detected a significant decrease in strain as compared with the fibers incubated for $6 \mathrm{~h}$ (Figure 3c). Therefore, the best mechanical properties were observed as early as after $2 \mathrm{~h}$ of incubation, but water resistance requires incubation for at least $5 \mathrm{~h}$. The increase in strain at break observed after 1 and $2 \mathrm{~h}$ of incubation, respectively, did not correlate with any detectable changes in overall secondary structure content as observed by FTIR spectroscopy (Figures 2 and 3). The increase in $\beta$-sheet content observed after 24 and $48 \mathrm{~h}$ (Figure 2) is linked to decreased strain, which fits with the current model that random coil, turn, and helical structures contribute to fiber extensibility [41-43]. However, there was no observed increase in tensile strength of the fiber which would have been expected to result from increased $\beta$-sheet content [44].

The changes in mechanical properties and water resistance were not accompanied by any significant morphological change as observed by light microscopy or SEM (Figures 4 and 5). However, an important observation was that the fibers had a "dual fiber" or flattened appearance (Figure S3), which had implications for the stress calculations (Figure S2). The tensile strength values, shown in Figure 3 and Table S1, were calculated assuming a circular cross-section of the fiber. This meant that if the fibers actually were not circular (but elliptical or dumbbell-shaped) we overestimated the fiber cross-sectional area by a factor of two, and thereby correspondingly underestimated the fiber tensile stress (Figure S2). Artificial silk fibers with dumbbell-shaped cross-sections have also been observed in NT2RepCT spinning setups which, instead of the pulled glass capillary, employed fluorinated ethylenepropylene tubes with round cross-sections [32], as well as other spinning setups and recombinant spidroins [45]. Notably, in these studies the cross-sectional area was also assumed to be circular when calculating tensile strength. By assuming a circular cross-sectional area it avoids overestimation of the mechanical properties, but complicates attempts to understand the basis for the mechanical properties of artificial silk fibers if it does not truly reflect the fiber morphology. The reasons for the observed dual fiber appearance in our spinning setup were not identified, but the the fiber morpholoiges were not a direct result of the shape of the hand-drawn glass capillary, as the nozzle was found to be circular (Figure 1).

Compared to silk spinning by a spider that happens in fractions of a second, our method requires significantly longer time for the fibers to become resistant to wet environments. This could depend on several factors including differences in flow dynamics, protein size and dope viscosity, ion and $\mathrm{pH}$ gradients, etc. In our spinning device, the spidroins were not sheared in the same way as natural spidroins are, since the silk fiber is pulled out from the duct of the spider, not extruded [46]. It is obvious that the spinning method has a significant impact on the properties of the resulting fibers, and increased incubation time combined with post-spin draw could be a promising route forward to achieve both higher strain at break and ultimate tensile strength of artificial fibers [45,47]. In summary, although the molecular mechanisms that are responsible for the observed change in properties remain to be determined, we herein present a feasible and simple way of improving strain at break and the resistance to aqueous solutions of biomimetic silk fibers.

\section{Conclusions}

Making spider silk proteins in heterologous hosts is the most promising route to successful production of artificial spider silk [9]. To obtain truly silk-like fibers, protein production and purification under non-denaturing conditions and subsequent biomimetic spinning methods are likely required [16]. In this work, we present a simple protocol using benign conditions to improve the mechanical properties and water resistance of biomimetically spun artificial spider silk fibers, both of which are important features for biomaterials intended for biomedical applications. 


\section{Materials and Methods}

\subsection{Preparation of the Spinning Dope}

The NT2RepCT protein was produced essentially as described in [31]. Briefly, an overnight culture was prepared using Luria broth (LB) media with 1:1000 kanamycin $(70 \mathrm{mg} / \mathrm{L})$ inoculated with a glycerol stock of Escherichia coli BL21DE3 harboring the plasmid pT7-6xHis-NT2RepCT. The culture was grown overnight at $30{ }^{\circ} \mathrm{C}$ with shaking $(200 \mathrm{rpm})$. One liter baffled shake flasks containing $1 \mathrm{~L}$ of LB media with kanamycin (1:1000) were inoculated with 1/100 of overnight culture and cultured at $30{ }^{\circ} \mathrm{C}$ with shaking (110 rpm.), until $\mathrm{OD}_{600}$ reached 0.6. Subsequently, the temperature was reduced to $20^{\circ} \mathrm{C}$ and growth continued until $\mathrm{OD}_{600}$ reached $0.8-0.9$, and then protein expression was induced by $1 \mathrm{M}$ isopropylthiogalactoside to a final concentration of $0.3 \mathrm{mM}$. Culturing continued overnight and cells were harvested by centrifugation, $7278 \times g$ for $20 \mathrm{~min}$. Cells were resuspended in $20 \mathrm{mM}$ Tris pH 8 (40 mL/L culture) and subjected to freezing at $-20^{\circ} \mathrm{C}$. Cells were lysed using a cell distributer (T-series Machine, Constant Systems Limited, Daventry, Northants, UK) at 30 kPsi equipped with a recirculating chiller (Neslab ThermoFlex ${ }^{\mathrm{TM}} 1400$, Thermo Scientific, Waltham, MA, USA) set to $4{ }^{\circ} \mathrm{C}$. The lysate was centrifuged at $27,000 \times \mathrm{g}$ at $4{ }^{\circ} \mathrm{C}$ for $30 \mathrm{~min}$. Purification was performed using the Ni-NTA column protocol as described in [31], however after loading the supernatants, two wash steps were conducted. The first wash was with $20 \mathrm{mM}$ Tris $\mathrm{pH} 8$ and the second wash was with $5 \mathrm{mM}$ imidazole. The protein was concentrated using an ultrafiltration spin column (Vivaspin 20, GE Healthcare, Chicago, IL, USA) with a $10 \mathrm{kDa}$ molecular weight cutoff, to a high concentration of approximately $300 \mathrm{mg} / \mathrm{mL}$. Spin columns were subjected to $4000 \times g$ for $20 \mathrm{~min}$ repeatedly until the final concentration was reached. To determine the protein concentration, $1 \mu \mathrm{L}$ of protein was diluted 1000 times, this was performed in triplicate. The absorbance of each sample was measured at $280 \mathrm{~nm}$ using a spectrophotometer, the protein concentrations were calculated using the molar extinction coefficient of NT2RepCT, $18,910 \mathrm{M}^{-1} \cdot \mathrm{cm}^{-1}$, and the average mean was recorded. Three batches of concentrated NT2RepCT protein dope were produced and loaded into separate $1 \mathrm{~mL}$ syringes with Luer Lok tip (BD, Franklin Lakes, NJ, USA) and frozen at $-20^{\circ} \mathrm{C}$.

\subsection{Artificial Spider Silk Spinning and Incubation}

Fiber spinning was performed following a modified protocol designed by Andersson et al. [31]. The syringe containing the protein dope was thawed at room temperature and connected to a $27 \mathrm{G}$ blunt end steel needle (B. Braun, Melsungen, Germany) with an outer diameter of $0.40 \mathrm{~mm}$. Round glass capillaries (G1 Narishige, Tokyo, Japan) with an outer diameter (O.D.) of $1.0 \mathrm{~mm}$ and inner diameter (I.D.) of $0.6 \mathrm{~mm}$ were pulled using a Micro Electrode Puller (Stoelting Co. 51217, Wood Dale, IL, USA) and cut to a tip diameter of 25-35 $\mu \mathrm{m}$ (Figure $1 \mathrm{~b}$ ). The needle was connected to the capillary by a series of two tubings. The first being a polyethylene tubing (BD Intramedic, Franklin Lakes, NJ, USA) with an O.D. of $1.09 \mathrm{~mm}$ and an I.D. of $0.38 \mathrm{~mm}$ encasing the needle with a $\sim 5 \mathrm{~mm}$ overhang and inserted $\sim 1 \mathrm{~cm}$ into the larger polyethylene tubing with an O.D. of $1.65 \mathrm{~mm}$ and an I.D. of $0.76 \mathrm{~mm}$ of which the capillary was inserted into, $\sim 5 \mathrm{~mm}$. The extensibility of the tubing allowed the components to be fitted together. A neMESYS low pressure (290 N) syringe pump (Cetoni, Korbußen, Germany) was used to extrude the protein into the collection bath $(500 \mathrm{mM} \mathrm{NaAc}$ and $200 \mathrm{mM} \mathrm{NaCl}, \mathrm{pH} 5$ at a flow rate of $17 \mu \mathrm{L} / \mathrm{min})$. For collection of the fibers, we used a custom made movable bidirectional motorized pulley system in which a circular roller with a $30 \mathrm{~mm}$ diameter was attached and submerged into the spinning buffer (Figure 1a). The roller was placed approximately $30 \mathrm{~cm}$ from the tip of the capillary and rotated counterclockwise. Extruding fibers were guided along the collection bath using a $1 \mu \mathrm{L}$ inoculation tube and picked up by the roller. After spinning, fibers were either removed immediately from the roller or were kept on the submerged roller in the spinning buffer for 1, 2, 6, 24, and $48 \mathrm{~h}$, respectively. Fibers were removed from the roller using surgical tweezers at each incubation time and placed on a black plastic sheet to dry. To pinpoint the exact incubation time that gave water resistant fibers, we performed a second series of experiments in which we incubated the fibers for 3, 5, and $5.5 \mathrm{~h}$. 
To determe the mechanical properties of the $0 \mathrm{~h}$ time point, the fibers were immediately collected onto six rotating diapositive slide frames mounted on a motorized wheel.

\subsection{Solubility Assay}

For each incubation time, two petri dishes were prepared in which one was filled with $\mathrm{dH}_{2} \mathrm{O}$ and the other was filled with filtered $1 \times$ PBS, pH 7.4. The petri dishes were placed on top of a black plastic sheet in order to visualize the fibers. Pieces of dried fibers from the respective incubation times were placed in $\mathrm{dH}_{2} \mathrm{O}$ and $1 \times \mathrm{PBS}$, respectively, and their integrity was observed by the naked eye after $24 \mathrm{~h}$, $48 \mathrm{~h}$, and 1 week.

\subsection{Fourier Transform Infrared (FTIR) Spectroscopy}

Incubated NT2RepCT fibers at the various time points were measured using a Vertex 70 instrument equipped with a Platinum-ATR and an MCT-detector (Bruker, Ettlingen, Germany) to obtain FTIR spectra on single fibers. To provide a stable environment for measuring, the instrument was purged with dry air which minimized water vapor and carbon dioxide interference with the sample spectra. For each sample condition, 6 fibers were measured; 3 fibers were measured in parallel to the infrared beam and the remaining 3 fibers were perpendicular to the beam. Prior to measuring each fibre, a background spectrum (200 scans) was obtained. Two hundred scans were recorded for each fiber at a resolution of $2 \mathrm{~cm}^{-1}$. The spectra were analyzed using Spectragryph, in which the 6 spectra were averaged, baseline subtracted, and then normalized to a maximum absorbance of 1 in the $1720-1590 \mathrm{~cm}^{-1}$ region. The second derivative spectra were processed with OPUS 5.5.

\subsection{Tensile Tests}

The fibers were mounted on a $1 \mathrm{~cm}$ square window cut in a paper frame following the procedure of Greco et al. [48]. The fibers were glued onto the frames using double sided tape. For tensile tests, a 5943-Instron tensile tester machine with a $5 \mathrm{~N}$ load cell was used. The imposed displacement speed was $60 \mathrm{~mm} \mathrm{~min}{ }^{-1}$. The engineering stress was calculated by dividing the measured force by the section of each tested thread. We measured the maximum diameter along the fiber with an optical microscope [49], and we measured it 5 times for each fiber by using the mean value for the calculation of the section's area, which was assumed to be circular. The engineering stress was obtained by dividing the force by the cross-sectional area. The engineering strain was obtained by dividing the total displacement by the gauge length. The Young's modulus was found by measuring the slope of the stress-strain curve in the initial linear elastic part. The toughness modulus was obtained by calculating the area under the stress-strain curve. We did not make any selection of the data obtained, the values for all fibers tested are shown in Table S1.

\subsection{Statistical Analysis}

\subsubsection{ANOVA Analysis}

One-way analysis of variance was performed to compare the mechanical properties of the fibers incubated in the spinning buffer for different times (pairwise comparison among groups). The two-tailed $p$-values were computed in Matlab ${ }^{\circledR}$ (MathWorks, Natick, MA, USA) and the significance was considered when $p<0.05$. For more details see Supplementary Materials.

\subsubsection{Light Microscopy}

Light microscopy images were collected using a Nikon eclipse TE300 inverted microscope equipped with a DFK 33UX249 camera from Imagingsource. For the $0 \mathrm{~h}$ incubation sample, the frames used to collect the fibers were placed on a glass microscopy slide and images recorded following $2 \mathrm{~h}$ of drying in air. For the 1, 2, 24, and $46 \mathrm{~h}$ samples fibers were removed from the submerged roller and 
allowed to dry in air for $2 \mathrm{~h}$ prior to being secured to glass microscopy slides using nail polish and subsequent recording of images.

\subsubsection{Scanning Electron Microscopy}

We investigated the morphology of the fibers with FE-SEM using a Zeiss Supra 40. The metallization was made by a sputtering machine Quorum Q150T with sputtering mode Pt/Pd 80:20 for 5 min.

Supplementary Materials: The Supplementary Materials are available online.

Author Contributions: Conceptualization, G.G. and A.R.; methodology, G.G. and J.F.; validation, G.G., J.F., A.B., J.J. and A.R.; investigation, G.G., J.F., T.A., B.S., F.G.B.; resources, A.R. and N.M.P.; data curation, G.G and J.F.; writing —original draft preparation, G.G., J.F., and A.R.; writing—review and editing, G.G., J.F., A.R., J.J. and N.M.P.; supervision, A.R.; project administration, A.R.; funding acquisition, A.R., N.M.P. All authors have read and agreed to the published version of the manuscript.

Funding: N.M.P. is supported by the European Commission under the FET Proactive ("Neurofibers") grant no. 732344, as well as by the Italian Ministry of Education, University and Research (MIUR) under the "Departments of Excellence" grant L. 232/2016, the ARS01- 01384-PROSCAN, and the PRIN-20177TTP3S grants. G.G. is supported by the PRIN-20177TTP3S grant. A.R. has received funding from the European Research Council (ERC) under the European Union's Horizon 2020 Research and Innovation programme (grant agreement no. 815357), the Center for Innovative Medicine (CIMED) at Karolinska Institutet and Stockholm City Council, Karolinska Institutet SFO Regen (FOR 4-1364/2019), the Swedish Research Council (2019-01257), and Formas (2019-00427).

Acknowledgments: The authors would like to thank Lorenzo Moschini, Antonella Motta and Claudio Migliaresi (Biotech, Mattarello, University of Trento) for their support with SEM facility.

Conflicts of Interest: The authors declare no conflict of interest. The funders had no role in the design of the study; in the collection, analyses, or interpretation of data; in the writing of the manuscript, or in the decision to publish the results.

\section{References}

1. Altman, G.H.; Diaz, F.; Jakuba, C.; Calabro, T.; Horan, R.L.; Chen, J.; Lu, H.; Richmond, J.; Kaplan, D. Silk-based biomaterials. Biomaterials 2003, 24, 401-416. [CrossRef]

2. Holland, C.; Numata, K.; Rnjak-Kovacina, J.; Seib, F.P. The Biomedical Use of Silk: Past, Present, Future. Adv. Healthc. Mater. 2019, 8, 1800465. [CrossRef]

3. Zhu, Q.; Tang, X.; Feng, S.; Zhong, Z.; Yao, J.; Zhong, Y. ZIF-8@SiO ${ }_{2}$ composite nanofiber membrane with bioinspired spider web-like structure for efficient air pollution control. J. Memb. Sci. 2019, 581, 252-261. [CrossRef]

4. Xu, B.; Yang, Y.; Yan, Y.; Zhang, B. Bionics design and dynamics analysis of space webs based on spider predation. Acta Astronaut. 2019, 159, 294-307. [CrossRef]

5. Yang, Y.; Greco, G.; Maniglio, D.; Mazzolai, B.; Migliaresi, C.; Pugno, N.M.; Motta, A. Spider (Linothele megatheloides) and silkworm (Bombyx mori) silks: Comparative physical and biological evaluation. Mater. Sci. Eng. C 2020, 107, 110197. [CrossRef]

6. Dellaquila, A.; Greco, G.; Campodoni, E.; Mazzocchi, M.; Mazzolai, B.; Tampieri, A.; Pugno, N.M.; Sandri, M. Optimized production of a high-performance hybrid biomaterial: Biomineralized spider silk for bone tissue engineering. J. Appl. Polym. Sci. 2019, 137, 48739. [CrossRef]

7. Allmeling, C.; Jokuszies, A.; Reimers, K.; Kall, S.; Choi, C.Y.; Brandes, G.; Kasper, C.; Scheper, T.; Guggenheim, M.; Vogt, P.M. Spider silk fibres in artificial nerve constructs promote peripheral nerve regeneration. Cell Prolif. 2008, 41, 408-420. [CrossRef] [PubMed]

8. Widhe, M.; Bysell, H.; Nystedt, S.; Schenning, I.; Malmsten, M.; Johansson, J.; Rising, A.; Hedhammar, M. Recombinant spider silk as matrices for cell culture. Biomaterials 2010, 31, 9575-9585. [CrossRef]

9. Salehi, S.; Koeck, K.; Scheibel, T. Spider Silk for Tissue Engineering Applications. Molecules 2020, 25, 737. [CrossRef]

10. Schacht, K.; Vogt, J.; Scheibel, T. Foams Made of Engineered Recombinant Spider Silk Proteins as 3D Scaffolds for Cell Growth. ACS Biomater. Sci. Eng. 2016, 2, 517-525. [CrossRef]

11. Vepari, C.; David, L.K. Silk as a biomaterial. Prog. Polym. Sci. 2007, 32, 991-1007. [CrossRef] [PubMed]

12. Jokisch, S.; Scheibel, T. Spider silk foam coating of fabric. Pure Appl. Chem. 2017, 89, 1769-1776. [CrossRef]

13. Arindam, B. Advances in Silk Science and Technology, 1st ed.; The Textile Institute: Boston, BSN, USA, 2015. 
14. Shah, D.U.; Porter, D.; Vollrath, F. Can silk become an effective reinforcing fibre? A property comparison with flax and glass reinforced composites. Compos. Sci. Technol. 2014, 101, 173-183. [CrossRef]

15. Rainer, F. Biology of Spiders, 3rd ed.; Oxford University Press: London, UK, 2011.

16. Rising, A.; Johansson, J. Toward spinning artificial spider silk. Nat. Chem. Biol. 2015, 11, 309-315. [CrossRef] [PubMed]

17. Edlund, A.M.; Jones, J.; Lewis, R.; Quinn, J.C. Economic feasibility and environmental impact of synthetic spider silk production from escherichia coli. N. Biotechnol. 2018, 42, 12-18. [CrossRef]

18. Fahnestock, S.R.; Bedzyk, L.A. Production of synthetic spider dragline silk protein in Pichia pastoris. Appl. Microbiol. Biotechnol. 1997, 47, 33-39. [CrossRef]

19. Scheller, J.; Henggeler, D.; Viviani, A.; Conrad, U. Purification of spider silk-elastin from transgenic plants and application for human chondrocyte proliferation. Transgenic Res. 2004, 13, 51-57. [CrossRef]

20. Menassa, R.; Zhu, H.; Karatzas, C.N.; Lazaris, A.; Richman, A.; Brandle, J. Spider dragline silk proteins in transgenic tobacco leaves: Accumulation and field production. Plant. Biotechnol. J. 2004, 2, 431-438. [CrossRef]

21. Scheller, J.; Conrad, U. Production of Spider Silk Proteins in Transgenic Tobacco and Potato. Mol. Farming 2005, 19, 171-181.

22. Fahnestock, S.R.; Irwin, S.L. Synthetic spider dragline silk proteins and their production in Escherichia coli. Appl. Microbiol. Biotechnol. 1997, 47, 23-32. [CrossRef]

23. Koeppel, A.; Holland, C. Progress and Trends in Artificial Silk Spinning: A Systematic Review. ACS Biomater. Sci. Eng. 2017, 3, 226-237. [CrossRef]

24. Rising, A.; Widhe, M.; Johansson, J.; Hedhammar, M. Spider silk proteins: Recent advances in recombinant production, structure-function relationships and biomedical applications. Cell. Mol. Life Sci. 2011, 68, 169-184. [CrossRef]

25. Lazaris, A.; Arcidiacono, S.; Huang, Y.; Zhou, J.F.; Duguay, F.; Chretien, N.; Welsh, E.A.; Soares, J.W.; Karatzas, C.N. Spider silk fibers spun from soluble recombinant silk produced in mammalian cells. Science 2002, 295, 472-476. [CrossRef]

26. An, B.; Tang-Schomer, M.D.; Huang, W.; He, J.; Jones, J.A.; Lewis, R.V.; Kaplan, D.L. Physical and biological regulation of neuron regenerative growth andnetwork formation on recombinant dragline silks. Biomaterials 2015, 48, 137-146. [CrossRef] [PubMed]

27. Xu, H.T.; Fan, B.L.; Yu, S.Y.; Huang, Y.H.; Zhao, Z.H.; Lian, Z.X.; Dai, Y.P.; Wang, L.L.; Liu, Z.L.; Fei, J.; et al. Construct synthetic gene encoding artificial spider dragline silk protein and its expression in milk of transgenic mice. Anim. Biotechnol. 2007, 18, 1-12. [CrossRef]

28. Hinman, M.B.; Jones, J.A.; Lewis, R.V. Synthetic spider silk: A modular fiber. Trends Biotechnol. 2000, 18, 374-379. [CrossRef]

29. Hijirida, D.H.; Do, K.G.; Michal, C.; Wong, S.; Zax, D.; Jelinski, L.W. ${ }^{13}$ C NMR of Nephila clavipes major ampullate silk gland. Biophys. J. 1996, 71, 3442-3447. [CrossRef]

30. Andersson, M.; Chen, G.; Otikovs, M.; Landreh, M.; Nordling, K.; Kronqvist, N.; Westermark, P.; Jörnvall, H.; Knight, S.; Ridderstråle, Y.; et al. Carbonic Anhydrase Generates CO2and H+That Drive Spider Silk Formation Via Opposite Effects on the Terminal Domains. PLOS Biol. 2014, 12, 8. [CrossRef]

31. Andersson, M.; Jia, Q.; Abella, A.; Lee, X.Y.; Landreh, M.; Purhonen, P.; Hebert, H.; Tenje, M.; Robinson, C.V.; Meng, Q.; et al. Biomimetic spinning of artificial spider silk from a chimeric minispidroin. Nat. Chem. Biol. 2017, 13, 262-264. [CrossRef]

32. Gonska, N.; Lopez, P.A.; Lozano-picazo, P.; Thorpe, M.; Gustavo, V.; Johansson, J.; Barth, A.; Rising, A. Structure-function relationship of artificial spider silk fibers produced by straining flow spinning. Biomacromolecules 2020, 21, 2116-2124. [CrossRef]

33. Venkatesan, H.; Chen, J.; Liu, H.; Kim, Y.; Na, S.; Wei, L.; Hu, J. Artificial spider silk is smart like natural one: Having humidity-sensitive shape memory with superior recovery stress. Mater. Chem. Front. 2019, 3, 2472-2482. [CrossRef]

34. Andreas, B. Infrared spectroscopy of proteins. Biochim. Biophys. Acta Bioenerg. 2007, 1767, 1073-1101.

35. Chirgadze, Y.N.; Nevskaya, N.A. Infrared spectra and resonance interaction of amide-I vibration of the antiparallel-chain pleated sheet. Biopolymers 1976, 15, 607-625. [CrossRef] [PubMed] 
36. Kubelka, J.; Keiderling, T.A. Differentiation of $\beta$-sheet-forming structures: Ab initio-based simulations of IR absorption and vibrational CD for model peptide and protein $\beta$-sheets. J. Am. Chem. Soc. 2001, 123, 12048-12058. [CrossRef] [PubMed]

37. Greco, G.; Pugno, N.M. Mechanical Properties and Weibull Scaling Laws of Unknown Spider Silks. Molecules 2020, 25, 2938. [CrossRef] [PubMed]

38. Elices, M.; Plaza, G.R.; Pérez-Rigueiro, J.; Guinea, G.V. The hidden link between supercontraction and mechanical behavior of spider silks. J. Mech. Behav. Biomed. Mater. 2011, 4, 658-669. [CrossRef] [PubMed]

39. Hagn, F.; Eisoldt, L.; Hardy, J.G.; Vendrely, C.; Coles, M.; Scheibel, T.; Kessler, H. A conserved spider silk domain acts as a molecular switch that controls fibre assembly. Nature 2010, 465, 239-242. [CrossRef]

40. Kronqvist, N.; Otikovs, M.; Chmyrov, V.; Chen, G.; Andersson, M.; Nordling, K.; Jo, H.; Wennmalm, S.; Widengren, J.; Meng, Q.; et al. Sequential pH-driven dimerization and stabilization of the N-terminal domain enables rapid spider silk formation. Nat. Commun. 2014, 5, 3254. [CrossRef]

41. Cranford, S.W.; Tarakanova, A.; Pugno, N.M.; Buehler, M.J. Nonlinear material behaviour of spider silk yields robust webs. Nature 2012, 482, 72-76. [CrossRef]

42. Keten, S.; Xu, Z.; Ihle, B.; Buehler, M.J. Nanoconfinement controls stiffness, strength and mechanical toughness of B-sheet crystals in silk. Nat. Mater. 2010, 9, 359-367. [CrossRef]

43. Nova, A.; Keten, S.; Pugno, N.M.; Redaelli, A.; Buehler, M.J. Molecular and nanostructural mechanisms of deformation, strength and toughness of spider silk fibrils. Nano Lett. 2010, 10, 2626-2634. [CrossRef] [PubMed]

44. Rockwood, D.N.; Preda, R.C.; Yücel, T.; Wang, X.; Lovett, M.L.; Kaplan, D.L. Materials fabrication from Bombyx mori silk fibroin. Nat. Protoc. 2011, 6, 1612-1631. [CrossRef] [PubMed]

45. Bowen, C.H.; Dai, B.; Sargent, C.J.; Bai, W.; Ladiwala, P.; Feng, H.; Huang, W.; Kaplan, D.L.; Galazka, J.M.; Zhang, F. Recombinant Spidroins Fully Replicate Primary Mechanical Properties of Natural Spider Silk. Biomacromolecules 2018, 19, 3853-3860. [CrossRef] [PubMed]

46. Vollrath, F.; Knight, D.P. Liquid crystal spinning of spider silk. Nature 2001, 410, 541-548. [CrossRef]

47. Koeppel, A.; Laity, P.R.; Holland, C. Extensional flow behaviour and spinnability of native silk. Soft Matter 2018, 14, 8838-8845. [CrossRef]

48. Greco, G.; Pantano, M.F.; Mazzolai, B.; Pugno, N.M. Imaging and mechanical characterization of different junctions in spider orb webs. Sci. Rep. 2019, 9, 5776. [CrossRef]

49. Blackledge, T.A.; Cardullo, R.A.; Hayashi, C.Y. Polarized light microscopy, variability in spider silk diameters, and the mechanical characterization of spider silk. Invertebr. Biol. 2005, 124, 165-173. [CrossRef]

Sample Availability: Samples of the compounds are not available.

(C) 2020 by the authors. Licensee MDPI, Basel, Switzerland. This article is an open access article distributed under the terms and conditions of the Creative Commons Attribution (CC BY) license (http://creativecommons.org/licenses/by/4.0/). 